\title{
Erosividade das Chuvas do Município de Gilbués, Piauí, Brasil
}

\author{
Cláudia Maria Sabóia de Aquino ${ }^{1}$; José Gerardo Bezerra de Oliveira $^{2}$, Renê Pedro de Aquino ${ }^{3}$ \\ ${ }^{1}$ Doutora em Geografia. Professora Adjunta na Universidade Federal do Piauí; cmsaboia@ gmail.com \\ 2Doutorem Manejo de Pastagens ( Universityof Arizona). Professor da Universidade Federal do Ceará; \\ jgboliv@gmail.com \\ 3Mestre em Geografia. Professor da Universidade Estadual do Piauí; rene.uespi@hotmail.com
}

\section{Eixo 3. Climatologia em diferentes níveis escalares: mudanças e variabilidades}

\section{Resumo:}

\begin{abstract}
Dentre os fatores integrantes da equação universal de perdas de solo, destaca-se o fator R, ou seja, a erosividade das chuvas. Objetivou-se com este trabalho calcular a erosividade da chuva (fator R) e gerar os mapas de espacialização deste fator para o município de Gilbués, Piauí. Os valores de erosividade das chuvas variaram de $6.518,8$ a $7.041,1 \mathrm{MJ} . \mathrm{mm} /$ ha.h.ano. Constatou-se o aumento dos valores de erosividade das chuvas a partir do mês de setembro, estando os maiores valores concentrados nos meses de Janeiro e fevereiro. Considerando a "vocação" natural da área à degradação é de fundamental importância e de relativa urgência que sejam traçadas estratégias de uso e manejo adequados da terra para este município, como uma tentativa de estabilizar a degradação ambiental em Gilbués.
\end{abstract}

Palavras-chave: potencial erosivo da chuva. Variabilidade espacial. degradação ambiental.

\section{1. Introdução}

A erosão dos solos, processo que consiste no desprendimento e arraste acelerado das partículas do solo causado pela água e pelo vento, é um problema que de há muito afeta as populações humanas. Grandes civilizações e impérios como o Mesopotâmico e o Romano decairam como resultado do desencadeamento dos processos de erosão que conduziram ao esgotamento dos seus solos (BERTONI \& LOMBARDI NETO, 1999).

Na erosão hídrica dois processos devem ser considerados: a) a ação das gotas das chuvas que golpeiam o solo, promovendo a desagregação das partículas de sua superfície, no local que sofre o impacto e o b) o transporte das partículas desagregadas tanto por salpicamento como por arraste do seu ponto de origem para um novo destino (EL-SWAIFY et al. 1982 e BERTONI \& LOMBARDI NETO, 1999).

A erosão do solo pela água é um processo complexo que depende de um conjunto de fatores básicos, tais como quantidade, intensidade e duração da chuva, natureza do solo, declividade da superfície do terreno e o tipo de uso da terra pelo homem. A ação destes fatores básicos é claramente modificada pela presença e natureza da cobertura vegetal (EL-SWAIFY et al. 1982, VIEIRA et al. 1996 e BERTONI \& LOMBARDI NETO, 1999). 
OS DESAFIOS DA GEOGRAFIA FÍSICA NA FRONTEIRA DO CONHECIMENTO Instituto de Geociências - Unicamp

Campinas - SP

28 de Junho à 02 de Julho de 2017

A erosão do solo tem sido estudada através de uma equação empírica desenvolvida e aperfeiçoada a partir de 1940 por pesquisadores norte americanos, denominada de Equação Universal de Perda de Solo - EUPS. A EUPS exprime a ação dos principais fatores que influenciam a erosão pela chuva. A equação desenvolvida por WISCHMEIER \& SMITH (1958) é expressa pela seguinte fórmula (HUDSON, 1981, BERTONI \& LOMBARDI NETO, 1999, VIEIRA, et al. 1996 e RENARD et al. 1997a):

$$
\mathrm{A}=\mathrm{R} \times \mathrm{K} \times \mathrm{L} \times \mathrm{S} \times \mathrm{P} \times \mathrm{C}
$$

em que:

A é a média anual de perda de solo, emt/ha,

R é a medida da erosividade da precipitação, em $\mathrm{MJ} / \mathrm{ha} . \mathrm{mm} / \mathrm{ha}$,

K é a erodibilidade do solo, em t/ha/ MJ/ha.mm/ha,

L é o comprimento do declive, em metros,

Sé o grau de declive, em percentagem,

C é o uso e manejo indicados pela relação entre perdas de solo de um terreno cultivado em dadas condições e as perdas correspondentes de um terreno mantido continuamente descoberto,

P é a prática conservacionista indicada pela relação de perdas de solo de um terreno cultivado com determinada prática (contornados ou com terraços) e as perdas em terreno sob cultivo enfileirado direto morro abaixo.

Lal (1988) aponta a erosividade da chuva (R) como sendo um fator físico significante para a magnitude e/ou intensidade da erosão do solo.

O conhecimento dos fatores que causam as perdas de solo é de fundamental importância para um planejamento conservacionista adequado e viável do ponto de vista econômico, deste modo este estudo objetivou estimar o fator Erosividade da Chuva - R e ainda espacializar os valores obtidos para este fator para o município de Gilbués localizado na porção sudoeste do Estado do Piauí.

\section{Material e Métodos}

O município de Gilbués localiza-se na mesorregião sudoeste piauiense (Figura 1). Geologicamente esta assentado sobre terrenos Paleozoicos da bacia Sedimentar do Maranhão-Piauí e Mesozoicos da bacia sedimentar São Franciscana. 
As formações geológicas constituintes destas bacias sedimentares apresentam litologias extremante vulneráveis a erosão representadas por siltitos, arenitos e conglomerados dispostos nas seguintes formações geológicas: Urucuia, Areado, Sambaíba, Pedra de Fogo, Piauí e Poti. (GOMES, 2004).

Os valores médios de precipitações anuais variam de 800 a aproximadamente $1200 \mathrm{~mm}$, com período chuvoso estendendo -se de novembro a abril . O trimestre mais úmido corresponde aos meses de dezembro, janeiro e fevereiro (GOMES, 2004).

A rede de drenagem é representada pelos altos cursos dos rios Parnaíba, Gurguéia, Uruçuí Preto e Uruçuí Vermelho. Vale destacar que a energia das águas destes rios em sendo maiores, dada à seção do rio potencializam os processos erosivos em Gilbués.

Os solos predominantes no município são os NeossolosQuartzarênicos e os latossolos nas áreas de chapadas e os Argissolos presentes nas áreas mais rebaixadas e mais dissecadas do munícipio. Sobre estes solos desenvolve-se uma vegetação do tipo Cerrado, bastante degradado, dado as atividades agropecuárias. (GOMES, 2004).

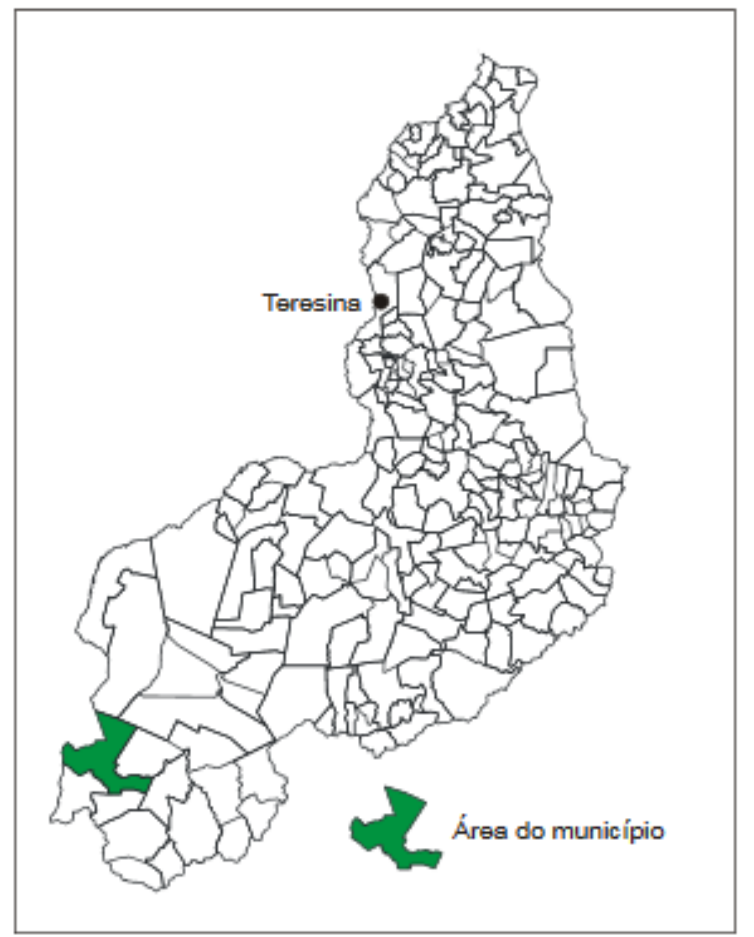

Figura 1 - Localização do município de Gilbués, Piauí, Brasil. Fonte:

\subsection{Procedimentos metodológicos}

A estimativa do fator erosividade das chuvas (R) baseou-se no método proposto por BERTONI \& LOMBARDI NETO (1999) para cálculo desse fator. A utilização deste método por ROSA (1995) e 

OS DESAFIOS DA GEOGRAFIA FÍSICA NA FRONTEIRA DO CONHECIMENTO
Instituto de Geociências - Unicamp
Campinas - SP
28 de Junho à 02 de Julho de 2017

CAVALIERI et al. (2001) para a estimativa do fator $\mathrm{R}$ em algumas localidades brasileiras, aliada a impossibilidade de determinação por métodos diretos deste fator justifica seu emprego neste trabalho.

A erosividade da chuva do munícipio de Gilbués baseou-se nos dados pluviométricos indicados em SUDENE (1990). Estes dados foram empregados na equação (1) proposta por BERTONI \& LOMBARDI NETO (1999). O processamento dos dados ocorreu a partir do emprego do pacote de programas USUAIS, desenvolvido por Oliveira e Sales (2016).

$$
\mathrm{EI}=67,355\left(\mathrm{r}^{2} / \mathrm{P}\right)^{0,85}(1)
$$

em que:

EI é a média mensal do índice de erosão, emMJ.mm/ha.h.ano,

ré a precipitação média mensal, em mm,

P é a precipitação média anual, em mm.

Foram empregados dados de 4 postos pluviométricos inseridos no munícipios e nas adjacências do mesmo para obtenção dos valores de erosividade.

Os valores de erosividade obtidos foram usados para confecção da carta de isoerodente seguindo-se os seguintes procedimentos:

a) alocação dos valores de $\mathrm{R}$ dos diversospostospluviométricosem um mapa de divisão municipal do estado do Piauí, considerando as coordenadasgeográficas de cada um;

b) para traçado das isolinhas foram estabelecidos três (3) intervalos considerando-se os valores mínimo e máximo obtidos para $\mathrm{R}$, posteriormente atribuiu-se a cada um dos intervalos uma denominação conforme Tabela 1.

Tabela 1 - Intervalos de R, com as denominações das classes correspondentes a cada intervalo.

\begin{tabular}{c|c}
\hline $\begin{array}{c}\text { Intervalos de R } \\
\text { (MJ.mm/ ha.h.ano) }\end{array}$ & Classes \\
\hline $\mathbf{6 5 0 0}<\mathbf{R} \leq 6750$ & Baixa \\
\hline $\mathbf{6 7 5 0}<\mathbf{R} \leq 7000$ & Moderada \\
\hline $\mathbf{7 0 0 0}<\mathbf{R} \leq 7250$ & Alta \\
\hline
\end{tabular}

c) por interpolação a partir dos valores limites dos intervalos de classes de R consideradas foram traçadas as linhas isoerosivas, que limitam zonas similares quanto a capacidade erosiva das chuvas expressa por este fator. 
XVII Simpósio Brasileiro

de Geografia Fisica Aplicad

I Congresso Nacional

de Geografia Física

\section{OS DESAFIOS DA GEOGRAFIA FÍSICA NA FRONTEIRA DO CONHECIMENTO \\ Instituto de Geociências - Unicamp \\ Campinas - SP \\ 28 de Junho à 02 de Julho de 2017}

\section{Resultados}

Os valores de erosividade para o município de Gilbués variaram de 6.518,8 a 7.041,1 MJ.mm/ ha.h.ano.

Constata-se que a área apresenta elevados valores de erosividade das chuvas, resultado dos valores significativos de precipitação registrados para o município que conforme Tabela 2 são superiores a $900 \mathrm{~mm}$ (posto Brejo) aproximando-se de $1200 \mathrm{~mm}$ (posto Boqueirão dos Felipes), posto tratar-se de um clima do tipo subúmido conforme Aquino, (2010).

Constata-se ainda conforme Tabela 2 que os valores de erosividade, de modo geral, aumentam com a precipitação, fato que está de acordo com as observações de CAMPOS FILHO et al. (1992) e BERTOL (1993 e 1994) que em suas pesquisas também evidenciaram o incremento dos valores da erosividade com a quantidade de chuva precipitada.

Tabela 2- Precipitação e Erosividade médias anuais dos postos pluviométricos inseridos no município de Gilbués, Piaú, e em seu entorno.

\begin{tabular}{c|c|c|c}
\hline $\begin{array}{c}\text { Postos } \\
\text { Pluviométricos empregados no estudo }\end{array}$ & $\begin{array}{c}\text { Precipitação } \\
(\mathrm{mm})\end{array}$ & $\begin{array}{c}\text { Erosividade Média } \\
\text { Anual } \\
(\text { MJ.mm/ ha.h.ano) }\end{array}$ & $\begin{array}{c}\text { Período de } \\
\text { coleta } \\
\text { de dados }\end{array}$ \\
\hline Gilbués & 1051 & $\mathbf{6 . 5 1 8 , 8}$ & $1962 / 85$ \\
\hline Barreiras do Piauí & 1103 & $\mathbf{6 . 6 0 5 , 6}$ & $1962 / 85$ \\
\hline Bela Vista & 1172 & $\mathbf{6 . 9 7 7 , 2}$ & $1962 / 85$ \\
\hline Boqueirão dos Felipes & 1181 & $\mathbf{7 . 0 4 1 , 1}$ & $1962 / 85$ \\
\hline \multicolumn{2}{|c}{ Fonte: os autores } \\
\hline
\end{tabular}

Depreende-se que a variação da precipitação ocorrida em Gilbués influencia a variabilidade nos padrões de erosividade das chuvas.

A Tabela 3 apresenta a distribuição dos valores de Erosividade Média Mensal dos postos pluviométricos analisados. Constata-se o aumento dos valores de erosividade das chuvas a partir do mês de setembro, estando os maiores valores concentrados nos meses de Janeiro e fevereiro.

Tabela 3- Erosividade: médias mensais dos postos pluviométricos inseridos no município de Gilbués, Piauí, e em seu entorno.

\begin{tabular}{c|c|c|c|c}
\hline \multirow{2}{*}{ Meses } & \multicolumn{4}{|c}{ Postos } \\
\cline { 2 - 5 } & Gilbués & $\begin{array}{c}\text { Barreiras do } \\
\text { Piaúi }\end{array}$ & Bela Vista & $\begin{array}{c}\text { Boqueirão dos } \\
\text { Felipes }\end{array}$ \\
\hline & \multicolumn{4}{|c}{$\begin{array}{c}\text { Erosividade Média Mensal } \\
\text { (MJ.mm/ ha.h.ano) }\end{array}$} \\
\hline Janeiro & 1835.7 & 1559.2 & 1768.2 & 1639.4 \\
\hline Fevereiro & 1172.8 & 1242.1 & 1333.2 & 1615.9 \\
\hline Março & 870.5 & 868.7 & 1047.5 & 749.3 \\
\hline Abril & 426.3 & 440.7 & 327.2 & 457.4 \\
\hline Maio & 23.1 & 10.8 & 10.4 & 12.6 \\
\hline Junho & $\mathbf{0 . 6}$ & 1.2 & 1.5 & 0.3 \\
\hline Julho & $\mathbf{0 . 0}$ & $\mathbf{0 . 0 7}$ & $\mathbf{0 . 1}$ & $\mathbf{0 , 0}$ \\
\hline
\end{tabular}




\begin{tabular}{c|c|c|c|c}
\hline Agosto & 0.2 & 1.3 & 0.5 & 0,1 \\
\hline Setembro & 34.8 & 17.4 & 39.5 & 31.8 \\
\hline Outubro & 222.0 & 408.4 & 425.6 & 419.2 \\
\hline Novembro & 993.4 & 874.6 & 895.0 & 971.6 \\
\hline Dezembro & 839.3 & 1181.0 & 1128.5 & 1143.4 \\
\hline \multicolumn{4}{|c}{ Fonte: os autores } \\
\hline
\end{tabular}

Os valores de erosividade obtidos foram usados para a confecção da carta de isoerodente indicado na Figura 2.

\section{EROSIVIDADE (R) DA PRECIPITAÇÃO EM GILBUÉS}

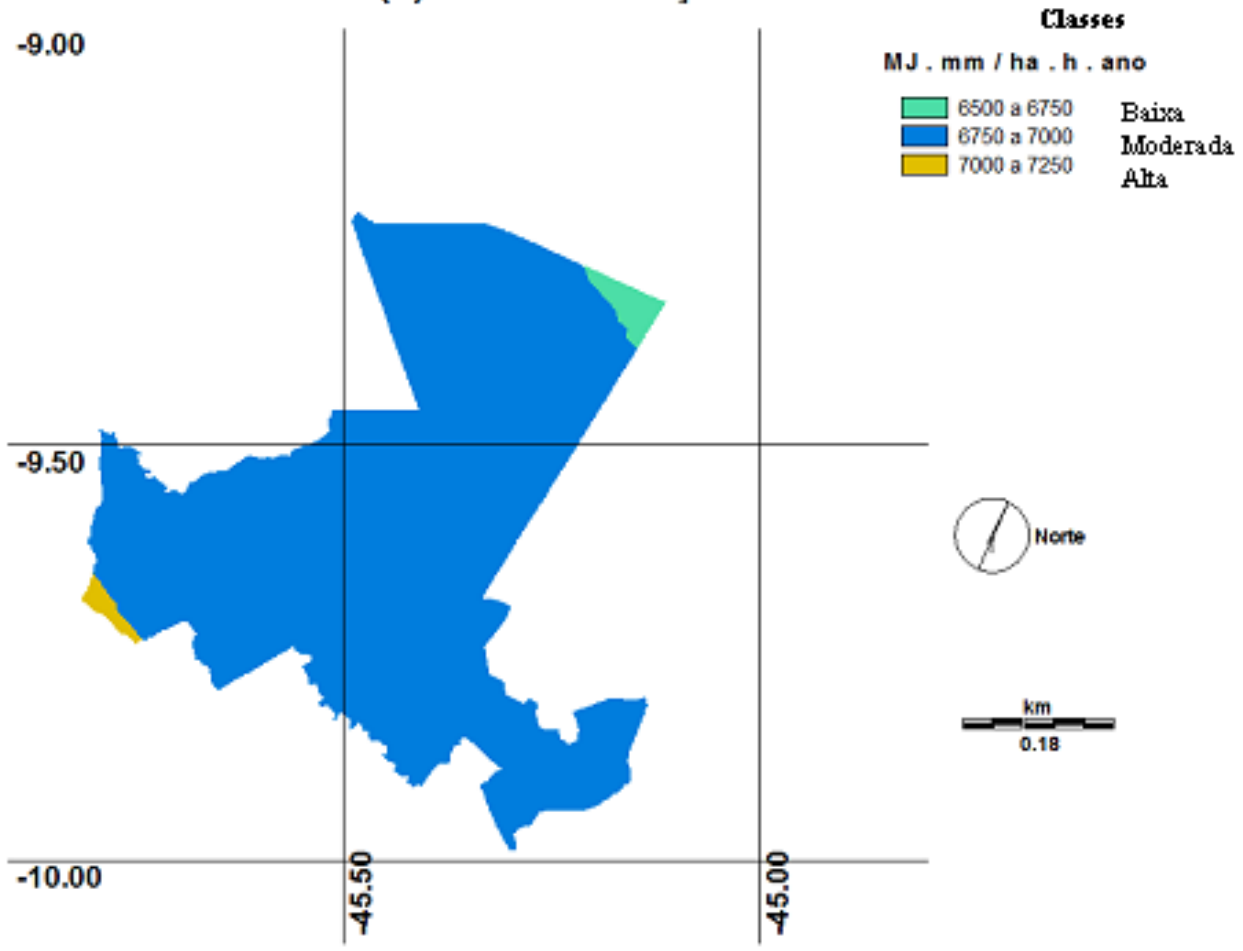

Figura 2 - Erosividade das chuvas do município de Gilbués, Piaú, Brasil.

De acordo com a Figura 2 há predomínio da classe de erosividade moderada na área de estudo.

O predomínio de erosividade moderada, de valores de precipitação acima de $1000 \mathrm{~mm}$, aliada a fragilidade litológica das formações geológicas da área de estudo, a rede de drenagem e ainda a intensa utilização do município para o desenvolvimento de atividades agropecuárias, vem desencadeando severos problemas de degradação ambiental na área, conforme Figura 3.

O processo de degradação verificado em Gilbués conferiu sua indicação pelo Ministério do Meio Ambiente como um dos Núcleos de Desertificação do Brasil (Figura 4). 


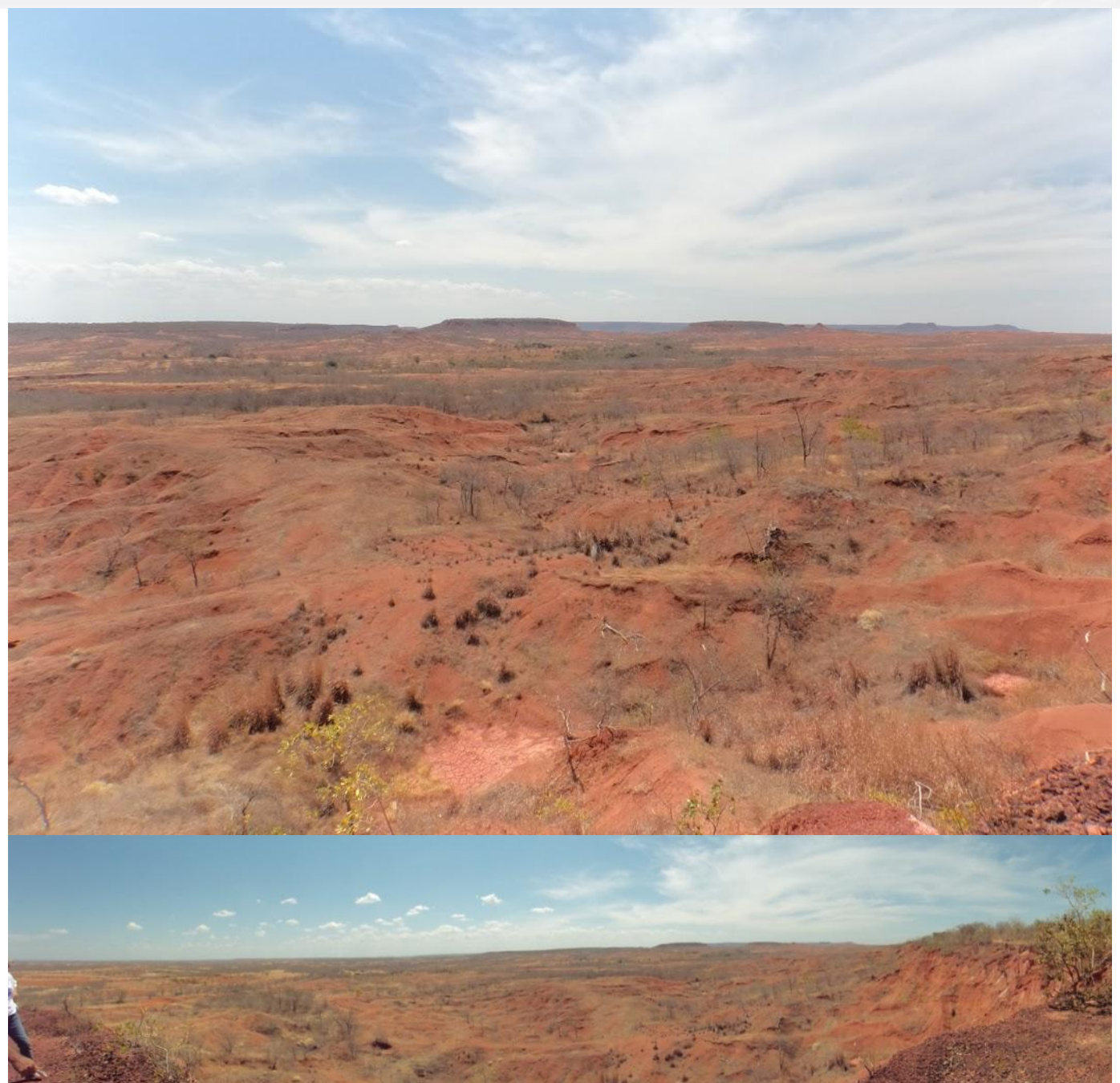

Figura 3 - Degradação da cobertura vegetal e dos solos município de Gilbués, Piauí, Brasil. Fonte: Valladares, 2016

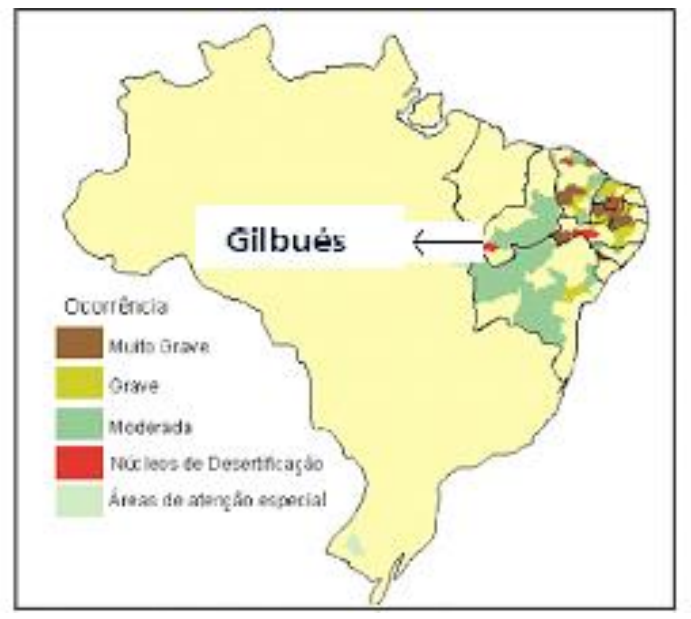

Figura 4 - Núcleos de desertificação no Brasil Fonte: MMA (2002) 


\section{Conclusões}

Os valores de erosividade das chuvas variaram de $6.518,8$ a 7.041,1 MJ.mm/ ha.h.ano. Constatou-se o aumento dos valores de erosividade das chuvas a partir do mês de setembro, estando os maiores valores concentrados nos meses de Janeiro e fevereiro. Os elevados valores de precipitação permitem inferir que a degradação do município de Gilbués não é resultante de escassez de água, mais sim da concentração desta em poucos meses do ano.

O predomínio de valores moderados de erosividade das chuvas para a área de estudo, aliado a i) fragilidade litológica representadas pelas Formações Geológicas Urucuia, Areado, Sambaíba, Pedra de Fogo, Piauí e Poti; ii) a elevada erosão hídrica promovida pelas nascentes de grandes rios Parnaíba, Gurguéia, Uruçuí Preto e Uruçuí Vermelho; iii), os significativos valores de precipitação concentrados em poucos meses do ano constatados na área de estudo imprimem ao município de Gilbués intenso processo de degradação ambiental.

Considerando a "vocação" natural da área a degradação é de fundamental importância e de relativa urgência que sejam traçadas estratégias de uso e manejo adequados da terra para este município, como uma tentativa de estabilizar a degradação ambiental em Gilbués.

\section{Referências}

AGUIAR, R. B. de. Projeto cadastro de fontes de abastecimento por água subterrânea, estado do Piauí: diagnóstico do município de Gilbués. Fortaleza: CPRM - Serviço Geológico do Brasil, 2004.

AQUINO, Cláudia Maria de Sabóiade . Estudo da degradação/desertificação no Núcleo de São Raimundo Nonato- PI. Aracaju , 2010. 238 p. Tese (Doutorado em Geografia) .Programa de Pós-graduação, Universidade Federal de Sergipe.

BERTOL, I. Avaliação da erosividade da chuva na localidade de Campos Novos (SC) no período de 1981 1990. Pesquisa Agropecuária Brasileira, Brasília, 29(9): 453 - 1458, 1994.

BERTOL, I. Índice de Erosividade (EI30) para Lages (SC) - $1^{\text {a }}$ Aproximação. Pesquisa Agropecuária Brasileira, Brasília, 28(4):515 - 521, 1993.

BERTONI, J. \& F. LOMBARDI NETO. Conservação do Solo., São Paulo, Ícone ed., 1999.

CAMPOS FILHO, O. R. I. de F. da SILVA, A . P. de ANDRADE \& J. C. LEPRUN. Erosividade da chuva e erodibilidade do solo no Agreste de Pernambuco. In: Pesquisa Agropecuária Brasileira, Brasília, 27(9): 1363 1370, 1992.

CAVALIERI, A., E. HAMADA, J. V. ROCHA \& F. LOMBARDI NETO. Estudo de degradação do solo com o uso do SIG - IDRISI. In: Caderno de Informações Georreferenciadas - CIG, 2001.

EL-SWAIFY, S.A.; E.W. DANGLER \& C.L.ARMSTRONG, Soilerosionbywater in thetropics. Honolulu: Researchextensionservice $n^{\circ}$ 024, Universityof Hawaii. 1982.

HUDSON, N. Soilconservation. Iowa StateUniversity Press. Iowa, 1981.

LAL, R. Erodibilityanderosivity. In: LAL, R. et al. Soilerosionresearchmethods. Washington: SoilandWaterConservationSociety, 1988. p. 141-160

OLIVEIRA, J.G.B.; SALES, M.C.L. Usuais: programas para uso em análise ambiental. Revista Equador (UFPI), Vol. 5, n. 2, p.36-60, Janeiro/Junho, 2016. 
RENARD, K.G.; L. D. MEYER \& G.R. FORSTER. Introductionandhistory. In: RENARD, K.G., G.R. FORSTER, G.A WEESIES, D. K. McCOOL\& D.C. YODER (Coordinators) - PredictingSoilErosionbyWater: A GuidetoConservation, Planning withtheRevised Universal SoilLossEquation (RUSLE) p 2 - 18, Washington: USDA/ARS, AgricultureHandbook nº 703, 1997

ROSA, R. O uso de sistemas de informação geográfica para estimativa de perda de solo por erosão laminar. In: ANAIS DO VI SIMPÓSIO NACIONAL DE GEOGRAFIA FÍSICA E APLICADA. Goiânia, 1995.

SUDENE. Dados Pluviométricos Mensais do Nordeste: Estado do Piauí. Recife, 1990.

VALLADARES, G.S. Fotografias. Fotografada em: Agosto 2016. Gilbués, 2016.

VIEIRA, M. N. F.; L. S. VIEIRA; P. C. T. C. SANTOS \& R. S. CHAVES. Levantamento e Conservação do Solo. Belém: Faculdade de Ciências Agrárias do Pará, 1996.

WISCHMEIER, W. H. \& D. D. SMITH. Rainfallenergyand its relationshiptosoilloss. Transactions, American Geophysical Union, 39(2): $285-291$. 